\title{
Over-the-counter medication patterns in households in Sharjah, United Arab Emirates
}

\author{
This article was published in the following Dove Press journal: \\ Risk Management and Healthcare Policy \\ 23 December 2013 \\ Number of times this article has been viewed
}

\section{Ashraf Ahmad Zaghloul' \\ Moetaz Elsergany ${ }^{2}$ \\ Nagwa Abou El-Enein' \\ Hamda Alsuwaidi ${ }^{3}$ \\ Mohamed Ayoub ${ }^{3}$}

'Health Administration and Behavioral Sciences Department, High Institute of Public Health, University of Alexandria, Alexandria, Egypt; ${ }^{2}$ e-School Health and Environmental Studies, Hamdan Bin Mohamed eUniversity, Dubai, United Arab Emirates; ${ }^{3}$ College of Health Sciences, University of Sharjah, United Arab Emirates.
Correspondence: Ashraf Ahmad Zaghloul Health Administration and Behavioral Sciences Department, High Institute of Public Health, University of Alexandria, 165, Al-Horreya Avenue, Alexandria, Egypt

Email azaghlou@sharjah.ac.ae
Background: Self-medication and acquisition of over-the-counter (OTC) medications are emerging community health issues. Besides being a cheap alternative for treating common illnesses, the behavior entails serious ramifications, such as medication wastage, increasing pathogen resistance, and adverse drug reactions. The present study was conducted to explore the extent of OTC medications in households in Sharjah, United Arab Emirates (UAE), including native UAE and expatriate families.

Methods: The study employed a population-based, cross-sectional, analytical study design. The study population included native and expatriate households residing in the Emirate of Sharjah, UAE. The snowball sampling technique was used, and the sample included a total of 335 households.

Results: Expatriate households acquired more OTC medications than did native households (adjusted odds ratio $[\mathrm{aOR}]=1.7$ ). The demographic determinants for expatriate households were number of family members $(\mathrm{aOR}=1.6)$, age of children in the family $(\mathrm{aOR}=1.8)$, and annual income $(\mathrm{aOR}=0.5)$. Expatriate households purchased more OTC medication practices than did native households $(\mathrm{aOR}=2.2)$. In the statistical sense, expatriate household practices were buying medication upon relatives' advice ( $\mathrm{aOR}=0.3$ ), storage condition of medication $(\mathrm{aOR}=2.4)$, and disposal of expired medication ( $\mathrm{aOR}=0.6$ ). The highest percentages of OTC medications in native and expatriate households were those related to gastric and ear, nose, and throat illnesses.

Conclusion: The presence of OTC medications in expatriate households was two-fold more common than in native households in Sharjah, UAE. There were significant associations for behaviors related to the reasons why OTC medications were purchased and stored within the household for both native and expatriate families.

Keywords: over-the-counter medication, pattern, odds ratio, household, Sharjah

\section{Background}

William Osler once commented that "The desire to take medicine is perhaps the greatest feature which distinguishes man from animals." ${ }^{\prime 1}$ This desire is probably the key factor for the practice of self-medication, which can be defined as obtaining and consuming drugs without the advice of a physician for diagnosis, prescription, or surveillance of treatment.

Studies on self-medication have revealed that it is a fairly common practice, especially in economically deprived communities. There is also a growing trend in self-care, which has both positive and negative aspects. ${ }^{2}$

Self-medication is widely practiced worldwide, and is often considered to be a component of self-care ${ }^{3}$ however, unlike other components of self-care, self-medication has the potential to cause harm as well as do good, because it involves the use of drugs. 
The World Health Organization (WHO) has appropriately pointed out that responsible self-medication can help in the prevention and treatment of diseases that do not require medical consultation, and represents a cheaper alternative for treating common illnesses; ${ }^{4}$ however, the medical literature suggests that over-the-counter (OTC) medications represent a serious issue: a study conducted in the United States concluded that about 3.1 million persons (5.3\%) aged between 12 and 25 years reported using OTC cough and cold medications to get high in 2006, according to the Substance Abuse and Mental Health Services Administration. ${ }^{5}$

Several studies have found that inappropriate selfmedication wastes resources, increases pathogen resistance, and generally entails serious health hazards such as adverse drug reactions, prolonged suffering, and drug dependence. ${ }^{6}$ Within the same context, such practices can aggravate the global problem of escalating medical costs through medication wastage. Medication wastage is defined as any drug product dispensed by prescription or purchased as an OTC medication that is never fully consumed. ${ }^{7}$ Medication wastage may arise through poor compliance of patients, excessive and irrational prescribing, or lack of controlled sales of prescription medications in community pharmacies. Self-medication is a common practice because it provides a low-cost alternative for people who cannot afford the high cost of clinical services and because many drugs are dispensed as OTC medications without a prescription from a registered medical practitioner. ${ }^{7,8}$

Self-medication practices differ from one place to another, and the behaviors are generally influenced by many factors, such as education, family, society, law, availability of drugs, exposure to advertisements, and, mostly, by the financial burdens of health care services, especially for those without medical insurance. ${ }^{9}$

All native UAE citizens are compulsorily insured through national and federal full-coverage health care plans that are exempt from monthly or annual premiums. Conversely, health insurance coverage remains optional for expatriates and is available through private health insurance firms and agencies with deductible premiums. Eventually, native citizens acquire medications free of charge, unlike expatriates, who acquire prescribed medications through full payment or on a co-payment basis, depending upon the type of health plan affiliation. The former factor (co-payment) for medically uninsured persons was the initial motivation for exploring OTC medications in households in Sharjah, UAE in the current study. There is a paucity of studies on self-medication and OTC medications in the Arab Gulf countries as well as the probable factors influencing their acquisition. ${ }^{7}$ The aspect of whether health insurance coverage represents a factor should be considered for explaining the patterns of OTC medication acquisition among native UAE and expatriate families.

The present exploratory study was conducted to compare OTC medications in households in Sharjah between native UAE and expatriate families.

\section{Methods \\ Study design}

The study employed a population-based, cross-sectional, analytical study design.

\section{Study population}

The study population included native and expatriate households within the Emirate of Sharjah, UAE.

\section{Ethical considerations}

The research proposal was submitted for scientific and ethical approval through the Medical Research Committee at the Medical Complex for Medical and Health Sciences Colleges, University of Sharjah, UAE. Both approvals were granted by mid-December 2012, at which time the researchers began to conduct the study.

The respondents in each household signed a written consent statement confirming that their participation in the study was of their own free will. The participants were informed of the option to refrain from joining the study or to withdraw at any phase of the data collection. The participants were informed through the consent form that all data collected would be kept confidential and destroyed after publication of the results of the study.

\section{Sampling}

The snowball sampling technique was employed to select the families included in the study. This technique is a special nonprobability method that is often used for hidden populations that are difficult for researchers to access or when the desired sample characteristic is rare. Snowball sampling relies on referrals from the initial subjects to generate additional subjects, thus the sample group appears to grow like a rolling snowball. Two native and expatriate families were initially approached, and the number of families continued to increase throughout the sample. By the time the predetermined data collection period was reached, the final sample size included 335 households. ${ }^{10}$ 


\section{Data collection}

The study was conducted from the beginning of January 2013 until May 2013. Relevant data were collected through a structured face-to-face interview with the head of each family after fixing an appointment. All OTC medications were compiled by the researchers and examined for their expiry date, cost, and presence or absence of original packaging. Medications were categorized after concluding the data collection phase according to their relevant effect on the body systems after conclusion of the data collection phase.

The data were recorded using a predetermined format that entailed two main divisions. Division 1 included demographic items: nationality; number of family members; age of children in the family; annual income; type of health insurance; and number of hospital visits per year. Division 2 included items related to the patterns of medication acquisition and storage: personal health care expenses; cost of expired medication; medication storage; buying OTC medication upon advice of relatives; condition of medication; and disposal of expired medication.

\section{Statistical analysis}

Statistical analyses were performed using Statistical Package for the Social Sciences (SPSS) software (v 17.0; IBM Corporation, Armonk, NY, USA). Data coding and entry were performed and variables with missing data were excluded from further statistical analysis. Exposure variables and confounders were screened for inclusion in the initial multivariate conditional logistic regression model. Candidate variables with values of $P<0.05$ were included in the multivariate binary logistic regression model. Separate binary logistic models were built. All exposure and confounder variables were categorized and binary-encoded $(0=$ reference group; $1=$ contrast group). Model 1 was built to calculate the odds ratios (ORs) for the presence of OTC medications among native and expatriate households. Subsequently, all demographic characteristics were introduced into the model to calculate the adjusted OR (aOR) for each confounding variable. All of the statistical tests were two-tailed, and values of $P<0.05$ were considered to be statistically significant.

A binary logistic regression was performed for the results of Block 1 to test the effects of nationality, number of family members, age of children in the family, annual income, type of insurance, and annual hospital visits on the presence of OTC medications. The results indicated that the predictor model provided a statistically significant improvement over the constant-only model: $\chi^{2}(6, \mathrm{n}=335)=52.7, P=0.0001$. The Nagelkerke $R^{2}$ indicated that the model accounted for $12.2 \%$ of the total variance. The correct prediction rate was about $58.5 \%$. The Wald test showed that two predictors significantly predicted the presence of OTC medications: age of children in the family and annual income.

A binary logistic regression was performed for the results of Block 2 to test the effects of nationality, personal health care expenses, cost of expired medication, medication storage, buying medication upon advice of relatives, condition of medication, and disposal of expired medication. The results indicated that the predictor model provided a statistically significant improvement over the constant-only model: $\chi^{2}(6, \mathrm{n}=335)=51.6, P=0.0001$. The Nagelkerke $R^{2}$ indicated that the model accounted for $18.5 \%$ of the total variance. The correct prediction rate was about $59.1 \%$. The Wald test showed that five predictors significantly predicted the presence of OTC medications: nationality, cost of expired medication, buying medication upon advice of relatives, condition of medication, and disposal of expired medication.

\section{Results}

Table 1 shows the ORs and aORs of the demographic characteristics of the study population by OTC medications in Sharjah households. Expatriate families acquired significantly more OTC medications than did native families (crude OR [95\% confidence interval]: 2.4 [1.5-3.7]). The aOR was reduced after adjusting for the demographic characteristics (1.7 [0.9-3.1]). No significant associations were detected, except for expatriate families with children aged above 3 years, who acquired more OTC medications than families with children aged less than 3 years (2.2 [1.4-3.5]). A significant association was detected after adjustment for the demographic variables in the model (1.8 [1.1-2.9]). The probability for expatriate families with annual incomes of less than 100,000 AED per year to acquire OTC medications was three times higher than for native families. The significant $O R$ after adjustment decreased to two-fold (0.5 [0.3-0.9]).

Table 2 shows the ORs and aORs of household practices by OTC medications in Sharjah households. The aOR for expatriate families was significantly higher, by two-fold, compared with that of native families $(2.2$ [1.3-3.6]) with regard to the variables introduced into the binary logistic model (Block 2); in other words, expatriate households had more OTC medication practices. The OR that expatriate families did not buy OTC medications upon advice of relatives was significantly higher, by three-fold, compared with native families $(0.3[0.2-0.5])$. The significant aOR remained constant after adjustment for the variables in the model $(0.3[0.2-0.5])$. Expatriate families showed a significant tendency to keep 
Table I ORs and adjusted ORs of demographic characteristics by presence of over-the-counter medications, Sharjah, 20I3

\begin{tabular}{|c|c|c|c|c|}
\hline \multirow[t]{2}{*}{ Variable } & \multicolumn{4}{|c|}{ Over-the-counter medications } \\
\hline & Total & $(n=173)$ & OR $(95 \% \mathrm{Cl})$ & Adjusted OR $(95 \% \mathrm{Cl})$ \\
\hline \multicolumn{5}{|l|}{ Nationality } \\
\hline UAE citizen & 207 & 124 & I (ref) & \\
\hline Expatriate & 128 & 49 & $2.4^{*}(1.5-3.7)$ & $1.7(0.9-3.1)$ \\
\hline \multicolumn{5}{|l|}{ Number of family members } \\
\hline$<5$ & 87 & 49 & I (ref) & \\
\hline 5 or more & 248 & 124 & $1.2(0.8-2.1)$ & $1.6(0.9-2.9)$ \\
\hline \multicolumn{5}{|l|}{ Age of children in the family } \\
\hline$\leq 3$ years & 187 & 115 & I (ref) & \\
\hline $3+$ years & 141 & 58 & $2.2 *(1.4-3.5)$ & $1.8^{*}(1.1-2.9)$ \\
\hline \multicolumn{5}{|l|}{ Annual income } \\
\hline$<100,000$ AED & 108 & 36 & I (ref) & \\
\hline $100,000+A E D$ & 227 & 137 & $0.3 *(0.2-0.5)$ & $0.5 *(0.3-0.9)$ \\
\hline \multicolumn{5}{|l|}{ Type of insurance } \\
\hline National & 207 & 109 & I (ref) & \\
\hline Private & 128 & 64 & I.I $(0.7-1.7)$ & I.I (0.7-I.8) \\
\hline \multicolumn{5}{|c|}{ Number of hospital visits per year } \\
\hline Less than 10 visits per year & 204 & 106 & I (ref) & \\
\hline 10 visits per year and above & $13 \mid$ & 67 & $1.03(0.6-1.6)$ & $1.2(0.7-1.8)$ \\
\hline
\end{tabular}

Note: $* p<0.05$.

Abbreviations: $\mathrm{Cl}$, confidence interval; OR, odds ratio; UAE, United Arab Emirates; AED, Arab Emirate Dirham.

expired OTC medications, compared with native families, for both the crude OR (0.6 [0.3-0.9]) and aOR (0.6 [0.4-0.9]). Expatriate families were twice as likely as native families to keep OTC medications in unknown packaging (crude OR:
$1.9[0.9-3.9])$, and the probability was significantly increased after adjusting for the other variables in the model (aOR: 2.4 [1.1-5.8]). No significant associations were detected between the other variables in the model.

Table 2 ORs and adjusted ORs of household practices by presence of over-the-counter medications, Sharjah, 20I3

\begin{tabular}{|c|c|c|c|c|}
\hline \multirow[t]{2}{*}{ Variable } & \multirow[t]{2}{*}{ Total } & \multicolumn{3}{|c|}{ Over-the-counter medications } \\
\hline & & $(n=173)$ & OR $(95 \% \mathrm{Cl})$ & Adjusted OR $(95 \% \mathrm{Cl})$ \\
\hline \multicolumn{5}{|l|}{ Nationality } \\
\hline UAE Citizen & 207 & 124 & I (ref) & \\
\hline Expatriate & 128 & 49 & $2.4^{*}(1.5-3.7)$ & $2.2 *(1.3-3.6)$ \\
\hline \multicolumn{5}{|l|}{ Personal health care expenses } \\
\hline$<10,000$ AED & 194 & 101 & I (ref) & \\
\hline I0,000 AED and above & $|4|$ & 72 & I.04 (0.7-I.6) & $0.7(0.3-1.6)$ \\
\hline \multicolumn{5}{|l|}{ Cost of expired medication } \\
\hline$<500$ AED & 237 & 128 & I (ref) & \\
\hline $500 \mathrm{AED}$ and above & 53 & 45 & $1.4(0.8-2.2)$ & $1.2(0.6-2.3)$ \\
\hline \multicolumn{5}{|l|}{ Medication storage } \\
\hline Special cabinet & 137 & 63 & I (ref) & \\
\hline (eg, kitchen, bathroom, bedroom medication) & 198 & 110 & $0.7(0.4-1.1)$ & $1.4(0.9-2.3)$ \\
\hline \multicolumn{5}{|l|}{ Buy medication upon relatives' advice } \\
\hline No & 226 & 97 & I (ref) & \\
\hline Yes & 109 & 76 & $0.3^{*}(0.2-0.5)$ & $0.3 *(0.2-0.5)$ \\
\hline \multicolumn{5}{|l|}{ Condition of medication } \\
\hline In its original package & 300 & 160 & I (ref) & \\
\hline No package; unknown medication & 35 & 13 & $1.9(0.9-3.9)$ & $2.4 *(I . I-5.8)$ \\
\hline \multicolumn{5}{|l|}{ Disposal of expired medication } \\
\hline Keep even if expired & 180 & 82 & I (ref) & \\
\hline Get rid of all & 155 & 91 & $0.6 *(0.3-0.9)$ & $0.6 *(0.4-0.9)$ \\
\hline
\end{tabular}

Note: $* P<0.05$

Abbreviations: $\mathrm{Cl}$, confidence interval; OR, odds ratio; UAE, United Arab Emirates; AED, Arab Emirate Dirham. 
Table 3 shows the number of OTC medications by pharmaceutical group. The highest percentages of OTC medications present in native and expatriate households were medications for gastric complaints ( $86 \%$ and $88.3 \%$, respectively), followed by medications for ear, nose, and throat complaints (77.8\% and $70.3 \%$, respectively). The lowest percentages of OTC medications in native households were nutrition supplements $(54.1 \%)$ and respiratory tract medications $(47.3 \%)$, whereas those in expatriate households were eye medications (41.4\%) and nutrition supplements (35.9\%).

\section{Discussion}

The main objective of the present study was to explore the association between the presence of OTC medications in households in Sharjah and the nationality of the families. The health system in UAE is currently undergoing reforms, which include expansion of the umbrella of health care insurance to all residents within the UAE. Expatriates are currently lacking the full coverage extended to citizens. The presence of OTC medications in expatriate households was 2.4 times higher than in native households. The aORs for purchasing OTC medications were in concordance with the demographic characteristics of the study population among the native and expatriate households. A larger family size has a higher economic burden for seeking health care, and increasing age of children in the family makes it more likely that the family will use OTC medications, for use by the entire family, as a way to minimize expenses as much as possible with regard to private medical consultations. Such behavior would increase the risks of incorrect dosage complications and antimicrobial resistance, as well as decrease the potency of the correct medications, especially for antibiotics. ${ }^{11,12}$ It was found that the highest percentages of OTC medications

Table 3 Number of over-the-counter medications by pharmaceutical group in households, Sharjah, 2013

\begin{tabular}{|c|c|c|c|c|}
\hline & \multicolumn{2}{|c|}{$\begin{array}{l}\text { Native } \\
\text { households }\end{array}$} & \multicolumn{2}{|c|}{$\begin{array}{l}\text { Expatriate } \\
\text { households }\end{array}$} \\
\hline & $\mathbf{N}$ & $\%$ & $\mathbf{N}$ & $\%$ \\
\hline \multicolumn{5}{|l|}{ Pharmacological group } \\
\hline Gastric medications & 178 & 86.0 & 113 & 88.3 \\
\hline Ear, nose, and throat medications & 161 & 77.8 & 90 & 70.3 \\
\hline Musculoskeletal medications & 152 & 73.4 & 85 & 66.4 \\
\hline Dermatological medications & 139 & 67.1 & 84 & 65.6 \\
\hline Eye medications & 132 & 63.8 & 53 & 41.4 \\
\hline Antibiotics & 127 & 61.4 & 75 & 58.6 \\
\hline Nutrition supplements & 112 & 54.I & 46 & 35.9 \\
\hline Respiratory tract medications & 98 & 47.3 & 59 & 46.1 \\
\hline
\end{tabular}

Note: Bold figures depict the highest and lowest percentages. among households were those related to gastric symptoms as well as ear, nose, and throat symptoms and complaints, and there is a need to mention the serious harm that such medications can cause on different systems in the body if used without the supervision of a physician. Other studies have concluded that antibiotics and cough medications comprise the highest percentages of purchased OTC medications. ${ }^{13,14}$

The global behavior of purchasing OTC medications is accompanied by other related behaviors. Results show that such behaviors are more commonly associated with expatriate households. Purchasing more OTC medications than required, storing OTC medications in unsuitable places within the household, and the condition of the medications (with or without original packaging and leaflets) were significant behaviors associated with expatriate households. ${ }^{15}$

It is recommended, by the authors, that the list of OTC medications should be diminished as a means toward protecting the community against the possible risks of complications from utilizing such medications. There is a need for a patient education campaigns, about both medicines in general and about the safe and appropriate use and storage of OTC medicines in particular. Such health education should be performed in the context of ordinary general practitioner consultations, but should also be backed up by media publicity and education in schools. Increasing the umbrella of public health insurance to cover expatriates would be another track toward the same objectives for a healthier community.

\section{Limitations}

The use of a convenient sampling design (snowball technique) limits generalization of the results. The absence of a comparative group from another emirate is another limitation. There was also a lack of cross-sectional designs directed to establish the relative risks of the outcome variables addressed in the study.

\section{Conclusion}

The association of OTC medications with expatriate households was found to be two-fold higher than in native households in Sharjah, UAE. There were significant associations for behaviors related to the reasons why OTC medications were purchased and stored within the household for both native and expatriate families. It is thus recommended that the list of OTC medications be revised by the Ministry of Health and necessary procedures followed toward diminishing the number of OTC medications as much as possible supported by evidence-based research, especially those medications that can have significant harmful effects 
or adverse events if administered on a nonprofessional basis.

\section{Acknowledgments}

The authors would like to acknowledge all the involved families for their full cooperation in answering the questionnaire and supplying the necessary data throughout the study.

\section{Disclosure}

The authors report no conflicts of interest in this work. The authors alone are responsible for the content and writing of the paper.

\section{References}

1. Montastruc JL, BagheriH, GeraudT, Lapeyre-Mestre M. [Pharmacovigilance of self-medication]. Therapie. 1997;52:105-110. French.

2. Porteous T, Bond C, Hannaford P, Sinclair H. How and why are nonprescription analgesics used in Scotland? Fam Pract. 2005;22:78-85.

3. Hughes CM, McElnay JC, Fleming GF. Benefits and risks of self medication. Drug Saf. 2001;24:1027-1037.

4. World Health Organization. The role of the pharmacist in self care and self medication. Available from: http://apps.who.int/medicinedocs/pdf/ whozip32e/whozip32e.pdf. Accessed on July 25, 2013.

5. Shi CW, Bayard MA. Abuse of over-the-counter medications among teenagers and young adults. Am Fam Physician. 2011;84:745, 750.
6. James H, Handu SS, Al Khaja KA, Otoom S, Sequeira RP. Evaluation of the knowledge, attitude and practice of self-medication among firstyear medical students. Med Princ Pract. 2006;15:270-275.

7. Abou-Auda HS. An economic assessment of the extent of medication use and wastage among families in Saudi Arabia and Arabian Gulf countries. Clin Ther. 2003;25:1276-1292.

8. Banerjee I, Bhadury T. Self-medication practice among undergraduate medical students in a tertiary care medical college, West Bengal. J Postgrad Med. 2012;58:127-131.

9. Martins AP, Miranda Ada C, Mendes Z, Soares MA, Ferreira P, Nogueira A. Self-medication in a Portuguese urban population: a prevalence study. Pharmacoepidemiol Drug Saf. 2002;11:409-414.

10. Zaghloul AA, Alsokair MK. Constructing a nurse appraisal form: a Delphi technique study. J Multidiscip Healthc. 2008;1:1-14.

11. Bradley $\mathrm{C}$, Bond $\mathrm{C}$. Increasing the number of drugs available over the counter: arguments for and against. Br J Gen Pract. 1995;45: $553-556$.

12. Widayati A, Suryawati S, de Crespigny C, Hiller JE. Self medication with antibiotics in Yogyakarta City Indonesia: a cross sectional population-based survey. BMC Res Notes. 2011;4:491.

13. Jaruseviciene L, Jurgute RR, Bjerrum L, Jurgutis A, Jarusevicius G, Lazaruse J. Enabling factors for antibiotic prescribing for upper respiratory tract infections: perspectives of Lithuanian and Russian general practitioners. Ups J Med Sci. 2013;118:98-104.

14. Shefrin AE, Goldman RD. Use of over-the-counter cough and cold medications in children. Can Fam Physician. 2009;55:1081-1083.

15. Badiger S, Kundapur R, Jain A, et al. Self-medication patterns among medical students in South India. Australas Med J. 2012;5:217-220.

\section{Publish your work in this journal}

Risk Management and Healthcare Policy is an international, peerreviewed, open access journal focusing on all aspects of public health, policy, and preventative measures to promote good health and improve morbidity and mortality in the population. The journal welcomes submitted papers covering original research, basic science, clinical \& epidemio-

\section{Dovepress}

logical studies, reviews and evaluations, guidelines, expert opinion and commentary, case reports and extended reports. The manuscript management system is completely online and includes a very quick and fair peerreview system, which is all easy to use. Visit http://www.dovepress.com/ testimonials.php to read real quotes from published authors. 